University of Wollongong

Research Online

Faculty of Engineering and Information

Faculty of Engineering and Information

Sciences - Papers: Part A

Sciences

$1-1-2014$

Performance of adjustable speed drives subject to regular voltage fluctuations

Kun Zhao

University of Wollongong, kz664@uowmail.edu.au

Philip Ciufo

University of Wollongong, ciufo@uow.edu.au

Sarath Perera

University of Wollongong, sarath@uow.edu.au

Follow this and additional works at: https://ro.uow.edu.au/eispapers

Part of the Engineering Commons, and the Science and Technology Studies Commons

Research Online is the open access institutional repository for the University of Wollongong. For further information contact the UOW Library: research-pubs@uow.edu.au 


\title{
Performance of adjustable speed drives subject to regular voltage fluctuations
}

\begin{abstract}
The impact of power quality disturbances on customer equipment has been a topic of interest to equipment manufacturers, electricity utilities, customers and to those involved in the development of electromagnetic compatibility standards. Recently, a new interest has developed in the possible impact of voltage fluctuations on customer equipment because of suggestions to relax voltage fluctuation limits and hence the flicker limits in power systems. With a view to contribute to this understanding, this paper investigates the performance of an adjustable speed drive (ASD) when subjected to sinusoidal regular voltage fluctuations. When the ASD is operating in open loop mode, the outcomes of experimental work illustrate that a fluctuating supply voltage will lead to an increase in the rectifier capacitor RMS current. Furthermore, the AC supply side fluctuations can pass through the rectifier and inverter unit and lead to a fluctuation in the induction motor stator current.
\end{abstract}

\section{Keywords}

fluctuations, regular, subject, drives, speed, adjustable, performance, voltage

Disciplines

Engineering | Science and Technology Studies

\section{Publication Details}

K. Zhao, P. Ciufo \& S. Perera, "Performance of adjustable speed drives subject to regular voltage fluctuations," in 16th IEEE International Conference on Harmonics and Quality of Power (ICHQP 2014), 2014, pp. 253-257. 


\title{
Performance of Adjustable Speed Drives Subject to Regular Voltage Fluctuations
}

\author{
Kun Zhao, Phil Ciufo* and Sarath Perera \\ School of Electrical, Computer and Telecommunications Engineering \\ University of Wollongong, Email: ppc@uow.edu.au*
}

\begin{abstract}
The impact of power quality disturbances on customer equipment has been a topic of interest to equipment manufacturers, electricity utilities, customers and to those involved in the development of electromagnetic compatibility standards. Recently, a new interest has developed in the possible impact of voltage fluctuations on customer equipment because of suggestions to relax voltage fluctuation limits and hence the flicker limits in power systems. With a view to contribute to this understanding, this paper investigates the performance of an adjustable speed drive (ASD) when subjected to sinusoidal regular voltage fluctuations. When the ASD is operating in open loop mode, the outcomes of experimental work illustrate that a fluctuating supply voltage will lead to an increase in the rectifier capacitor RMS current. Furthermore, the AC supply side fluctuations can pass through the rectifier and inverter unit and lead to a fluctuation in the induction motor stator current.
\end{abstract}

Index Terms-Voltage fluctuations, flicker, adjustable speed drives (ASDs), rectifier capacitor, induction motor current.

\section{INTRODUCTION}

The impact of power quality disturbances on customer equipment has been a topic of interest to equipment manufacturers, electricity utilities, customers and to those who are involved in the development of electromagnetic compatibility standards. With the traditional incandescent lamp being replaced by other, higher efficiency types which are less sensitive to voltage fluctuations suggests relaxation of voltage fluctuation limits and hence the flicker limits in power systems [1], [2]. However, the potential detrimental effects caused by increased voltage fluctuations on other electrical equipment should be considered before existing flicker limits are altered, where further detailed work should be undertaken, such as laboratory tests, considering voltage fluctuation levels greater than those which correspond to currently used flicker compatibility levels.

The terminal characteristics of single-phase capacitor filtered rectifiers, widely used in electronic power supplies, have been investigated in [3] where it was shown that the RMS value of the filter capacitor current substantially increases as the modulation frequency of the applied sinusoidally modulated supply voltage is increased. Such an increase will lead to additional heating within the capacitor, thus impacting on its life, possibly causing premature failure. In addition, the impact of regular voltage fluctuations on mains connected induction motors has been investigated and the outcomes indicate that

NOTICE: this is the authors' version of a work that was accepted for publication in the ICHQP proceedings. Changes resulting from the publishing process, such as peer review, editing, corrections, structural formatting, and other quality control mechanisms may not be reflected in this document. Changes may have been made to this work since it was submitted for publication. A definitive version was subsequently published in the Proceedings of the 16th IEEE International Conference on Harmonics and Quality of Power, May 2014, DOI:10.1109/ICHQP.2014.6842863 the stator and rotor RMS current magnitudes can be affected significantly by the voltage fluctuations and this effect worsens as the modulation frequency and the modulation depth of the supply voltage increase [4].

Adjustable speed drives (ASDs) using squirrel cage induction motors are the primary choice in many variable speed applications [5]. The design and/or selection of the power supply network for ASDs, in particular the electromagnetic compatibility environment, needs to be considered carefully since ASDs generate unwanted harmonics which pollute the supply network. At the same time, there is also the possibility for ASDs to be affected by the disturbances that exist in the supply network. The main reasons that cause ASD maloperation can be summarised as follows [6]:

- Power electronic components cannot sustain over- or under-voltage so the drive controller or protection unit will detect the sudden change in operating conditions and isolate the drive to prevent damage to the electronic components.

- Increased AC currents during a sag or the over-current at the end of a sag causes the DC-link capacitor to accumulate charge, causes an over-current trip.

- The process driven by the motor will not be able to tolerate the drop in the speed or torque caused by the voltage interruption or a deep sag.

Protection systems of ASDs are not designed to guard against excessive voltage fluctuations since the maximum of voltage change level is rarely beyond $\pm 10 \%$. However, the previous investigations indicate that the cumulative effect arising from voltage fluctuations will cause both a rectifier capacitor and an induction motor to incur increased losses, resulting in a potential lifetime reduction [3] [4]. Accordingly, the potential impact on an ASD and induction motor combination from voltage fluctuations is investigated in this paper. The focus of the analysis is the DC-link capacitor ripple current and the induction motor stator current behaviour.

This paper is organised as follows: background details in relation to voltage fluctuations and flicker as a power quality issue are reviewed in Section II. The characteristics of a PWM VSI-fed adjustable speed drive are reviewed in Section III. The performance of ASDs and induction motor stator current profiles when subject to regular voltage fluctuations are investigated in Section IV, including the DC-link capacitor current behaviour and the stator current profiles under different loading levels. Conclusions are presented in Section V.

\section{ReView of Voltage Fluctuations And Flicker}

Power system voltage fluctuations and hence flicker are evaluated using short term and long term flicker severity indices $P_{s t}$ and $P_{l t}$. For rectangular voltage fluctuations the 
threshold of flicker perception is defined using the $P_{s t}=1.0$ curve [7] for incandescent lamps which covers a voltage modulation frequency range between approximately $0.5 \mathrm{~Hz}$ and $32 \mathrm{~Hz}$. Related to this curve, for flicker perception, at the low modulation frequency end, the depth of modulation corresponds to approximately $10 \%$, whereas the minimum depth of modulation is approximately $0.3 \%$ that corresponds to a modulation frequency around $8.8 \mathrm{~Hz}$. The flickermeter, as defined in IEC 61000-4-15 [8], is normally used to measure the severity of voltage fluctuations and hence the flicker.

From a theoretical perspective, although voltage fluctuations can be considered to be regular with a constant level of variation, in practice, voltage fluctuations are quite random and are difficult to be used in systematic studies. For this reason it is common to use regular voltage fluctuations in many flicker related studies. This paper uses sinusoidal amplitude modulation to study the induction motor behaviour. Such a waveform can be defined using:

$$
\begin{aligned}
v(t) & =V_{p} \sin \left(2 \pi f_{c} t\right)\left[1+m \sin \left(2 \pi f_{m} t\right)\right] \\
m & =\frac{\Delta V}{2 V_{p}}
\end{aligned}
$$

where, $V_{p}$ is the amplitude of the fundamental AC voltage, $f_{c}$ is the fundamental frequency and modulation frequency is expressed as $f_{m}$. The voltage magnitude variation is represented by $\Delta V$ and the modulation depth is represented by $m$. Alternatively, (1) can be expressed as:

$$
\begin{aligned}
v(t)=V_{p} \sin \left(2 \pi f_{c} t\right) & +\frac{m V_{p}}{2} \sin \left(2 \pi\left(f_{c}+f_{m}\right) t-\frac{\pi}{2}\right) \\
& +\frac{m V_{p}}{2} \sin \left(2 \pi\left(f_{c}-f_{m}\right) t+\frac{\pi}{2}\right)
\end{aligned}
$$

According to (2), the fluctuating voltage source contains two frequency components; a super-synchronous frequency, also known as the upper-sideband (USB) and a sub-synchronous frequency, also known as the lower-sideband (LSB). These two components will be given specific attention in the work presented in the paper.

\section{Characteristic OF THE PWM VSI-FED AdJustable SpeEd Drive}



Fig. 1. Schematic diagram of the PWM VSI-fed adjustable speed drive

A typical ASD consists of a front-end rectifier to convert AC voltage to DC voltage and an inverter for generating a variable frequency, variable voltage power supply, as illustrated by the circuit diagram of Fig. 1. For most ASDs, the rectifier is a three-phase system. Inverter types can commonly be classified as either a voltage source inverter (VSI) with a large shunt capacitor, or a current source inverter (CSI) with a large series inductor. Both inverter types will typically use pulsewidth modulation (PWM) to generate the switching patterns. Occasionally, in VSIs, a DC line inductance is added to reduce the rectifier current ripple and further reduce the harmonic distortion to satisfy the AC side harmonic injection requirements. In this paper, the VSI-fed drive with DC-link capacitor is the focus because of the large number of applications of this type of configuration in industry.

Main source of low frequency harmonic currents is the three-phase rectifier whereas the PWM inverter contributes to the high frequency harmonics. The abundant harmonics not only pollute the AC supply network, but also increase stress on the devices within, for example, the inverter and the rectifier DC-link capacitor. Aside from the harmonic components resulting from three-phase rectifier, the high frequency harmonics generated by PWM switch signals will increase the capacitor power loss, resulting in an accelerated ageing process of the DC-link capacitor [9]-[11].

However, when the ASD system is subject to regular voltage fluctuations, the DC-link capacitor current characteristics take a different form compared to normal. The question arises as to whether the magnitude of sideband currents around the fundamental frequency are more significant than that of harmonic currents that arises from inverter switching frequency. For an open loop inverter unit of the type used in the current research, whether or not the fluctuating voltage can pass through the inverter unit to affect the stator current of connected induction motor needs investigation which is one of the aims of this paper.

\section{PERformance of ASDs Supplying An Induction MOTOR}

A. Performance of ASD with the Induction Motor - Full Load



Fig. 2. Experimental set-up of the VSI-fed ASD with an induction motor

As an example, an ASD was selected to drive a $5.5 \mathrm{~kW}$, $50 \mathrm{~Hz}$ induction motor, as illustrated in Fig. 2. In the experimental work, the programmable power supply connected to the ASD can be considered as an ideal voltage source that is superimposed with positive and negative sequence voltages with various modulation frequencies.

For the case when the induction motor is operating at full load, the results showing the DC-link capacitor current waveform and the corresponding spectral analysis are illustrated in Fig. 3. In this scenario, the system is subjected to a sinusoidally modulated voltage with a $10 \%$ magnitude depth at a modulation frequency of $15 \mathrm{~Hz}$. The reader should note 


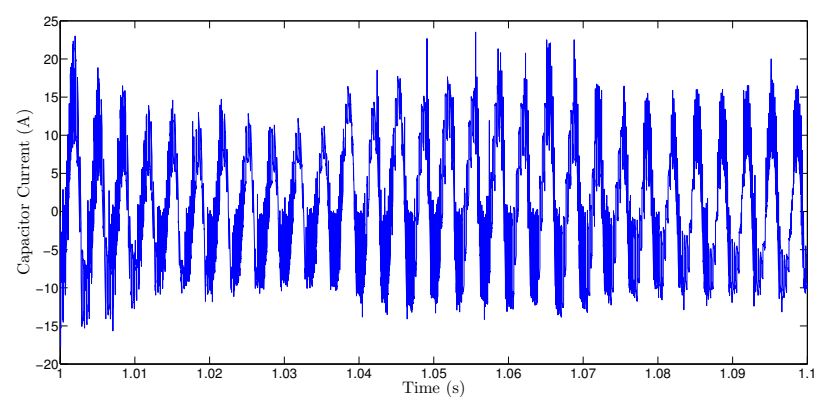

(a) Capacitor current waveform

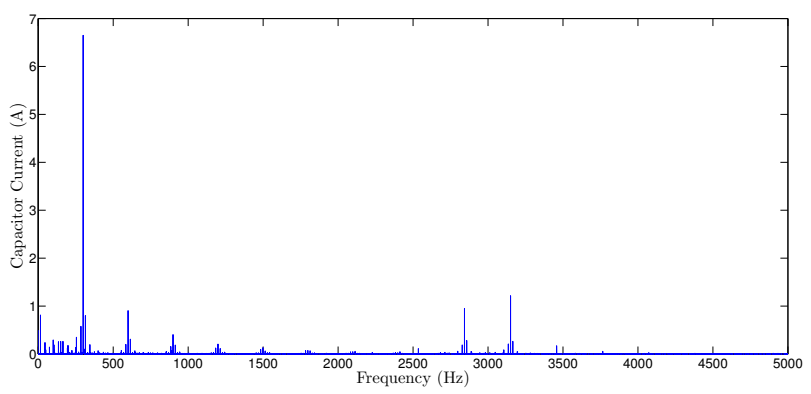

(b) Capacitor current frequency spectrum

Fig. 3. Experimental observations of capacitor current, $\frac{\Delta V}{V}=10 \%$ and $f_{m}=15 \mathrm{~Hz}$, full load

that this is a large voltage fluctuation, unlikely to be observed in a real distribution network but was selected for the purpose of obtaining easily measurable fluctuating current magnitudes.

The modulation frequency component, which leads to upper-sideband and lower-sideband current components centred around the capacitor current fundamental frequency and the other harmonic orders, can be noted in Fig. 3(b). When compared to the case of capacitor performance under a normal power supply, the capacitor will draw less current in some half cycles and draw more current in some half cycles. The peak current changes constantly due to the fluctuating supply voltage waveform. Aside from the low frequency capacitor current, there are some high frequency signals, which arise from the inverter switching control signals.

The induction motor stator current results that are shown in Fig. 4 when the ASD is subjected to $10 \%$ voltage change and $15 \mathrm{~Hz}$ modulation frequency indicates that the AC side voltage fluctuations transfer to the motor. Clearly, the fluctuating voltage not only causes capacitor current fluctuations, but can also pass through the inverter and cause stator current to fluctuate, which is illustrated in Fig. 4(a).

The stator current spectrum in Fig. 5, indicates that the $15 \mathrm{~Hz}$ modulation frequency is reflected as an upper-sideband and lower-sideband around the fundamental current and the high frequency components which arise as a result of inverter switching. The sideband currents around the fundamental frequency current are significant, which is clearly evident in Fig. 5(a). The results show that the sidebands around the fundamental frequency current components are much greater than the harmonic current resulting from the inverter switching effects, which is clearly evident from Fig. 4(b). Thus, in the induction motor stator current, the low frequency components dominate the total stator current, rather than the high frequency

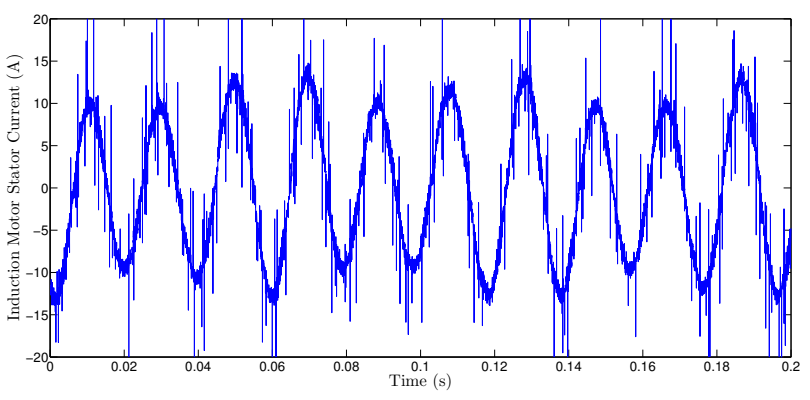

(a) Induction motor stator current waveform

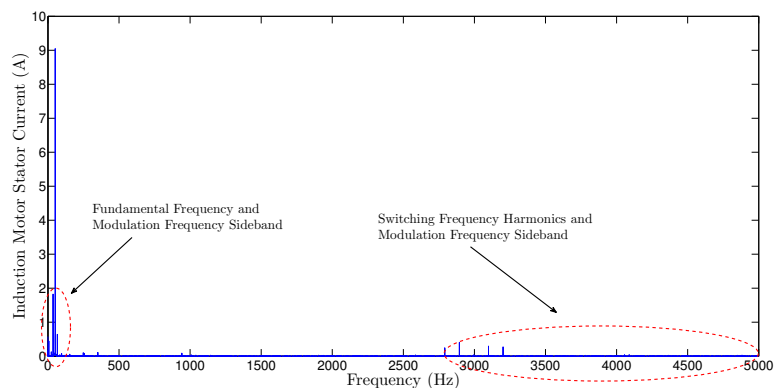

(b) Induction motor stator current frequency spectrum

Fig. 4. Experimental observations of stator current, $\frac{\Delta V}{V}=10 \%$ and $f_{m}=$ $15 \mathrm{~Hz}$, full load

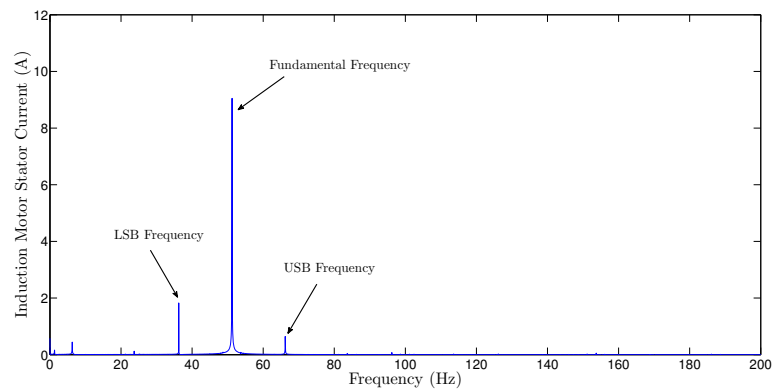

(a) Stator current low frequency spectrum

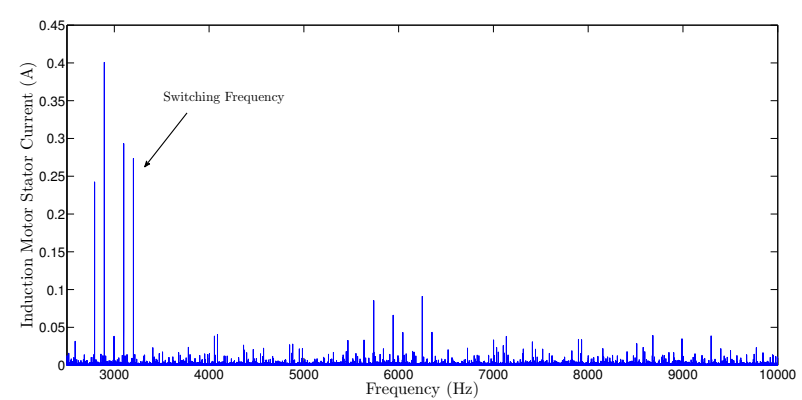

(b) Stator current high frequency spectrum

Fig. 5. Stator current low frequency and high frequency spectrum, full load

harmonics.

To observe the variations in capacitor current and stator current over a wide range of voltage fluctuating conditions, the modulation depth was varied from $2 \%$ to $10 \%$ while varying the modulation frequency from $1 \mathrm{~Hz}$ to $35 \mathrm{~Hz}$. The corresponding variation of the normalised RMS current magnitudes are shown in Fig. 6. Normalising has been carried out using the capacitor current and rated stator current magnitudes obtained with no voltage fluctuations. Fig. 6 illustrate the capacitor RMS current and stator RMS current trends with increasing 


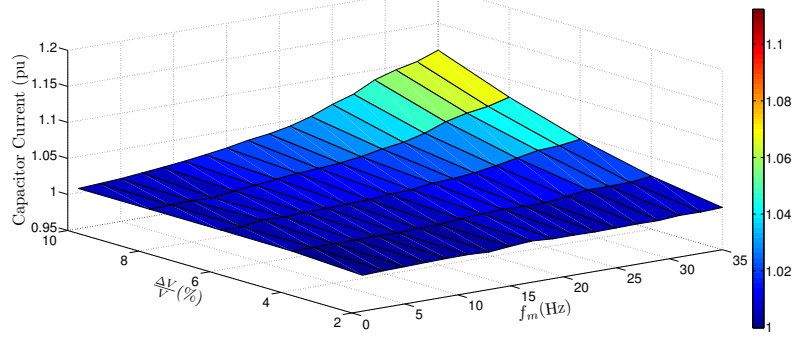

(a) Capacitor current experiment results



(b) Stator current experiment results

Fig. 6. Variation of capacitor RMS current and stator RMS current with $\frac{\Delta V}{V}$ and $f_{m}$, full load

voltage fluctuation levels and increasing modulation frequency.

\section{B. Performance of ASDs with the Induction Motor - Light Load}

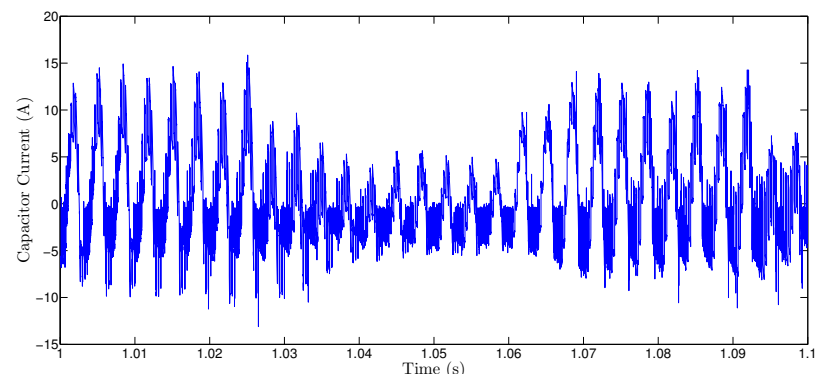

(a) Capacitor current waveform

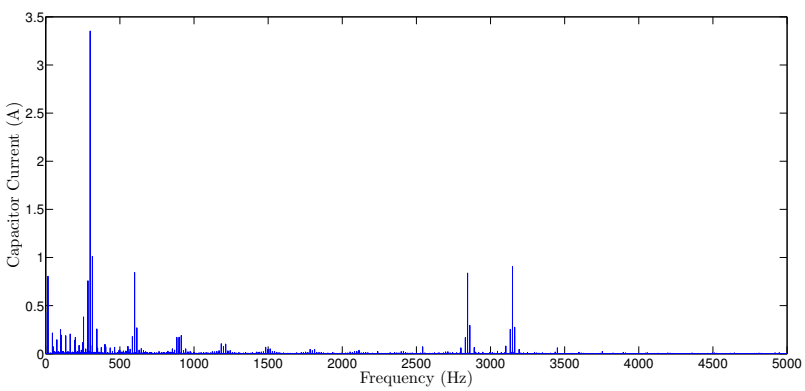

(b) Capacitor current frequency spectrum

Fig. 7. Experimental observations of capacitor current, $\frac{\Delta V}{V}=10 \%$ and $f_{m}=15 \mathrm{~Hz}$, light load

For the case where the induction motor is lightly loaded, the results showing the DC-link capacitor current waveform and the corresponding spectral analysis are illustrated in Fig. 7.
In this scenario, the ASD is subjected to a sinusoidally modulated voltage with a $10 \%$ magnitude depth at a modulation frequency of $15 \mathrm{~Hz}$. As in the case of heavy load, the modulation frequency $(15 \mathrm{~Hz})$ creates an upper-sideband and lower-sideband components around the capacitor current fundamental frequency and higher order harmonics. These are clearly seen in Fig. 7(b). Compared with the heavily loaded case, for the same voltage fluctuation level, the capacitor current waveform is seen to fluctuate more. The fundamental current and the harmonic current magnitudes are less than those in the heavily loaded case as expected. However, the magnitudes of the sideband components caused by the fluctuating voltage do not show any obvious reduction. This can be observed by a sideband magnitude comparison in Figs. 3(b) and 7(b) arise since they lead to losses within the machine compared to fundamental component which correspond to useful mechanical output.

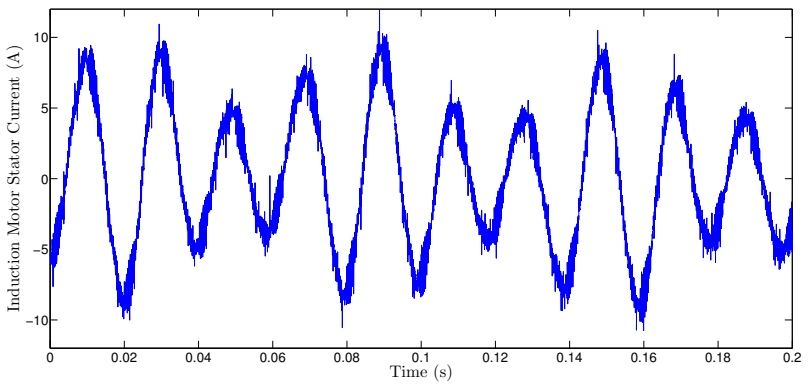

(a) Induction motor stator current waveform

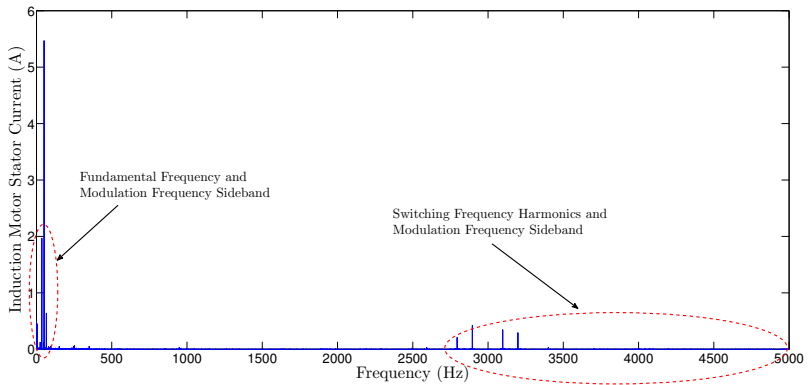

(b) Induction motor stator current frequency spectrum

Fig. 8. Experimental observations of stator current, $\frac{\Delta V}{V}=10 \%$ and $f_{m}=$ $15 \mathrm{~Hz}$, light load

The heavily loaded case shows that the fluctuating supply voltage not only causes capacitor current fluctuations, but it also passes through the inverter and causes stator current fluctuations. This is also the case when the load on the induction motor is light. The related stator current and frequency spectra are illustrated in Figs. 8 and 9.

The $15 \mathrm{~Hz}$ modulation frequency is also reflected as an upper-sideband and as a lower-sideband around the fundamental current and the higher order harmonics, as seen in Fig. 9. Just as with the capacitor current characteristic at light load, the stator fundamental current magnitude is less than that in the full load case, which means the stator current fluctuates when the machine is subjected to the same voltage fluctuations. The magnitudes of the stator current sideband components do not show an obvious reduction even though the stator fundamental current reduces significantly, as evident from in Fig. 9(a). The results show that the sideband components around the 
fundamental frequency current are significantly larger than the harmonic currents resulting from the inverter operation, which is clearly evident from Fig. 8(b). Thus, for an induction motor connected to a light shaft load, the inverter influence on stator current harmonics is less than the sideband effects caused by supply voltage fluctuations.

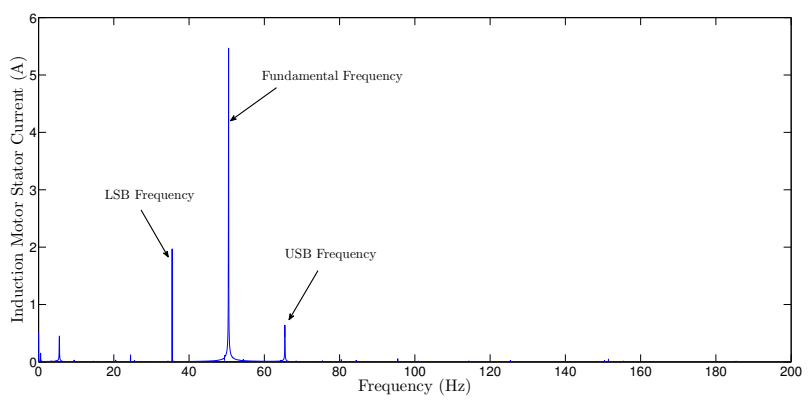

(a) Stator current low frequency spectrum

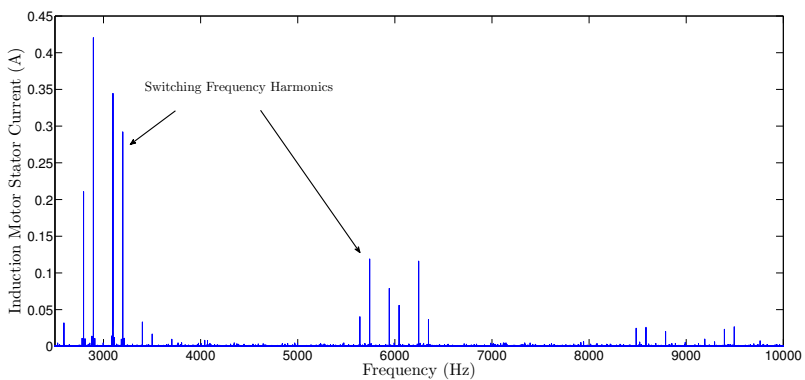

(b) Stator current high frequency spectrum

Fig. 9. Stator current low frequency and high frequency spectrum, light load

To observe the variations of capacitor current and stator current over a wide range of voltage fluctuating conditions, modulation depth was varied from $2 \%$ to $10 \%$ while modulation frequency is varied from $1 \mathrm{~Hz}$ to $35 \mathrm{~Hz}$. The corresponding variation of the normalised RMS current magnitudes are shown in Fig. 10. Normalising has been carried out using the capacitor current and the stator current magnitudes obtained with no voltage fluctuations and with heavy load. For a $10 \%$ voltage fluctuation level at $35 \mathrm{~Hz}$, the stator current RMS value increased by almost $10 \%$. Thus, the AC side voltage fluctuations can pass through the inverter unit and cause stator current fluctuation.

\section{CONCLUSIONS}

The experimental performance of an adjustable speed drive (ASD) and induction motor with different loading levels was investigated in this paper when the ASD was subjected to regular voltage fluctuations.

As the ASD is operating in open loop mode, a fluctuating supply voltage will lead to an increase in the rectifier capacitor RMS current. The magnitudes of capacitor current sideband components arising from voltage fluctuations around the fundamental frequency are much larger than the higher order harmonic currents which are generated by the switching frequency. Just as for the single-phase rectifier capacitor case, the capacitor RMS current keeps increasing as the voltage change and modulation frequency increase.

The induction motor stator current profiles indicate that the AC supply side fluctuations pass through the rectifier and



(a) Capacitor current experiment results

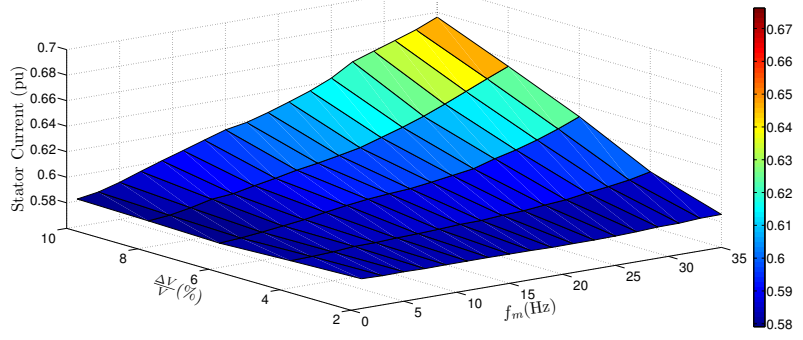

(b) Stator current experiment results

Fig. 10. Variation of capacitor RMS current and stator RMS current with $\frac{\Delta V}{V}$ and $f_{m}$, light load

inverter unit, leading to a fluctuation in the induction motor stator current, and further resulting in the RMS value of stator current increasing under both full and light load conditions. If the voltage magnitude changes are large enough, the ASD will trip due to the operation of the thermal protection. The required voltage change level decreases as the modulation frequency increases as higher voltage change and modulation frequency will lead to a greater stator RMS current through the ASD.

\section{REFERENCES}

[1] R. Cai, J. Cobben, J. Myrzik, J. Blom, and W. Kling, "Flicker responses of different lamp types," IET. Generation, Transmission Distribution, vol. 3, no. 9, pp. 816-824, Sep. 2009.

[2] C. Medeiros and J. de Oliveira, "Effects of voltage fluctuation associated to flicker limits on equipments performance," in 10th International Conf. Harmonics and Quality of Power (ICHQP), vol. 1, Oct. 2002, pp. 347352 vol.1.

[3] K. Zhao, P. Ciufo, and S. Perera, "Rectifier capacitor filter stress analysis when subject to regular voltage fluctuations," IEEE Trans. Power Electronics, vol. 28, no. 7, pp. 3627-3635, July 2013.

[4] _ _ "Induction motors subject to regular voltage fluctuations: Stator and rotor current analysis from a heating perspective," in IEEE 15th International Conf. Harmonics and Quality of Power (ICHQP), 2012, pp. 642-648.

[5] T. Jahns and E. Owen, "Ac adjustable-speed drives at the millennium: how did we get here?" IEEE Trans. Power Electronics, vol. 16, no. 1, pp. 17-25, Jane 2001

[6] M. Bollen and L. Zhang, "Analysis of voltage tolerance of ac adjustablespeed drives for three-phase balanced and unbalanced sags," IEEE Trans. Industry Applications, vol. 36, no. 3, pp. 904-910, May/June 2000.

[7] Electromagnetic compatibility (EMC)-Part 3-7: Limits - Assessment of emission limits for the connection of fluctuating installations to $M V, H V$ and EHV power systems, IEC 61000-3-7. Edition 2.0 (2008-02) Std.

[8] Electromagnetic compatibility (EMC)-Part 4-15: Testing and measure ment techniques - Flickermeter - Function and design specifications, IEC 61000-4-15. Edition 2.0 (2010-08) Std.

[9] F. Kieferndorf, M. Forster, and T. Lipo, "Reduction of dc-bus capacitor ripple current with PAM/PWM converter," IEEE Trans. Industry Applications, vol. 40, no. 2, pp. 607-614, March-April 2004. 
[10] K.-W. Lee, M. Kim, J. Yoon, S. B. Lee, and J.-Y. Yoo, "Condition monitoring of dc-link electrolytic capacitors in adjustable-speed drives," IEEE Trans. Industry Applications, vol. 44, no. 5, pp. 1606-1613, Sep.Oct. 2008.

[11] K. Lee, T. Jahns, G. Venkataramanan, and W. Berkopec, "Dc-bus electrolytic capacitor stress in adjustable-speed drives under input voltage unbalance and sag conditions," IEEE Trans. Industry Applications, vol. 43, no. 2, pp. 495-504, March-April 2007. 